\title{
Trajectories across the lifespan of possession-self relationships is $^{2}$
}

\author{
Katerina Karanika ${ }^{a, *}$, Margaret K. Hogg ${ }^{b}$

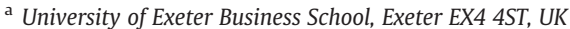 \\ b Consumer Behavior \& Marketing, Lancaster University, LA14YX, UK
}

\section{A R T I C L E I N F O}

\section{Article history:}

Received 1 June 2011

Received in revised form 1 November 2011

Accepted 1 December 2011

Available online $\mathrm{xxxx}$

\section{Keywords:}

Consumer behavior

Relationships with possessions

Possessions' meanings

Phenomenology

\begin{abstract}
A B S T R A C T
Research on valued possessions tends to concentrate on only one phase of the consumption cycle at a time (acquisition, consumption or disposition) and largely neglects consumers' varying experiences of their special possessions over time. The present study uses phenomenological interviews to examine consumers' experiences with their valued possessions throughout the consumption cycle in order to address the gap in the understanding of the way the person-object relationship evolves. The life-story technique that the study follows helps informants unfold experiences and relationships over time and captures a sequence of respondents' experiences with their important possessions/products. Findings suggest that the way consumers experience their valued possessions over time depends on the possession's meaning. This article maps how the relationship of the self to the valued possession follows three main trajectories depending on the reason for valuing the possession. Possessions that consumers in this study value for representing affiliation tend to have increasing importance to the self, while possessions respondents value for differentiating the self from others tend to have declining importance to the self. Possessions informants value for associating them with recreation, security, nurturance and transitions regarding loved-ones, tend to have steady importance to the self. The trajectories often reflect life events and transitions in the consumer's life-story and do not necessarily reflect the object/product use-life.
\end{abstract}

(c) 2011 Elsevier Inc. All rights reserved.

\section{Background}

The trajectories which track the longitudinal relationship between the self and valued possessions invite further investigation (Kleine \& Baker, 2004). This paper examines consumers' experiences with their self-relevant possessions and products throughout the consumption cycle, thereby addressing an important gap in the understanding of the different trajectories of how the self relates to material objects over time. This area of research is very topical within consumer behavior as the research focus increasingly moves from pre-purchase and purchase decision making to the consumption experiences before, during or after purchase.

Individuals choose, construct and communicate their identities through the objects they possess, deriving meaning from their possessions and investing possessions with meaning (Belk, 1988; Dittmar, 1991; Elliot \& Wattanasuwan, 1998; Hogg \& Michell, 1996; Holt, 2002; Richins, 1994a; 1994b; Wallendorf \& Arnould, 1988; Wicklund

\footnotetext{
is The authors gratefully thank Eminegul Karababa, Alex Thompson, the reviewers and chairs of the La Londe Marketing conference (2011) for their very helpful feedback and comments.

* Corresponding author.

E-mail addresses: K.Karanika@exeter.ac.uk (K. Karanika), m.hogg@lancaster.ac.uk (M.K. Hogg).
}

\& Goliwitzer, 1982). Relationships with material objects are not static (Shimp \& Madden, 1988), they are process phenomena (Fournier, 1998); they evolve and change over a series of interactions and in response to fluctuations in the contextual environment. Belk, Wallendorf, and Sherry (1989) refer to "successive investments and divestitures of meaning associated with a consumer's relationship with an object" (p.14) and Fournier (1998) conducting research on relationships that characterize consumer-brand bonds also refers to consumers' ongoing relationships with brands. However, literature on people and their special possessions (Belk, 1988; Csiicszentmihalyi \& Rochberg-Halton, 1981; Richins, 1994b; Wallendorf \& Arnould, 1988) tends to neglect consumers' dynamic relationships with their possessions. How a consumer relates to and experiences a specific object can change over time (Myers, 1985). As the self develops, the consumer develops new attachments to possessions and disposes of or abandons old attachments to possessions, reflecting increasing identification with emerging selves and detachment from old, unwanted or unneeded, selves. Earlier research on valued possessions tends to concentrate on one phase of the consumption cycle at a time (acquisition, consumption or disposition); for example Bell, Holbrook, and Solomon (1991) and Olmsted (1991) concentrate on acquisition motivations for valued possessions; Grayson and Shulman (2000), Richins (1994a) and Wallendorf and Arnould (1988) concentrate on consumption practices for valued possessions; while Price, Arnould, and Curasi (2000), Roster (2001) and Young and Wallendorf (1989) examine disposition practices for valued possessions. 
Although these earlier studies suggest that the consumer does not necessarily value, relate to, experience and use a possession in a similar way throughout the consumption cycle, research largely overlooks how a consumer's experiences with his or her valued possessions change throughout the consumption cycle. Scholars make some potentially contradictory suggestions about the way consumers' experiences with their possessions change over time. One view is that consumers care more for their possessions when they are brand new and then lose interest in possessions over time (Belk, 1988; Richins \& Block, 1986), as desire decreases after the object is acquired (Belk, Ger, \& Askegaard, 2003). Prior work also focuses on disposition associated with changes in life cycle stages and diminished object meaning (Curasi, Price, \& Arnould, 2004; Lastovicka \& Fernandez, 2005). The other view suggests that the consumer cares increasingly about his/her possessions as the individual cultivates meanings through interactions with an object over time; that is objects become "layered" with meaning via personal attention over time (i.e. increased object value over time) (Belk, 1988; Belk et al., 1989; Csiicszentmihalyi \& Rochberg-Halton, 1981; Richins, 1994a, 1994b; Wallendorf \& Arnould, 1988). Therefore, Epp and Price (2010) argue that in contemporary consumer culture, object biographies depict uncertain trajectories (Hurdley, 2006; Kopytoff, 1986), as personal biographies depict uncertain trajectories, as evidenced in diverse identity practices (Ahuvia, 2005; Reed \& Bolton, 2005; Warde, 2005). This assumption of objects' uncertain trajectories represents a potentially significant gap in the understanding of the way the self extends through objects most notably by building or integrating possessions into the self; or maybe eventually removing or discarding the possessions from the self.

A "possession focus", that as Applbaum and Jordt (1996) suggest (drawing on Kopytoff (1986) and the biography of objects) involves focusing on the possession itself and following it into the 'world' in which it is consumed, would provide an opportunity to discover consumers' experiences of the possession/product over its trajectory and how these experiences might differ over the possession's life-cycle.

\section{Research design and method}

A phenomenological examination is in line with the discoveryoriented research goals (Wells, 1993) and promises to generate rich data as consumer-object relationships link to lived experience and the individual's psycho-socio-cultural context. Therefore, this phenomenological research study (Kvale, 1983; Thompson, Locander, \& Pollio, 1990; Thompson, Pollio, \& Locander, 1989) explores Greek female consumers' experiences with their meaningful possessions and products. According to Dittmar (1992) although gender differences in special possessions are real, men and women have more in common when it comes to reasons for attachments. However, the literature portrays gender differences in the reasons people value possessions (e.g. Belk, 1992; Belk \& Wallendorf, 1997; Kamptner, 1989; Sherman \& Newman, 1977-78; Wallendorf \& Arnould, 1988; Wapner, Demick, \& Redondo, 1990). Therefore, because gender, as a major social category, is likely to influence consumption experiences, this study focuses on only women's consumption experiences in order to reduce the complexity of examining both women's and men's consumption experiences across age groups. Convenience and snowball sampling guided the recruitment of thirty participants, ten from each age span: 18-33, 34-49 and 50-65. Variations in age/ cohort and life-cycle allow for research attention to be paid to socio-cultural, economic and life stage factors. Table 1 below summarizes informants' personal characteristics:

In line with the discovery-oriented project goals, phenomenological interviewing (Colaizzi, 1978; Kvale, 1983; Thompson et al., 1990, 1989) allows the elicitation of full descriptions of experiences, compared with more structured approaches to inquiry. These types of qualitative studies regularly recruit smaller samples than surveybased research (e.g. Ahuvia, 2005; Fournier, 1998; Thompson, 1996; Thompson et al., 1990). The phenomenological interview is semistructured. The respondents largely drive the conversation. The interviewer employs short descriptive questions and specifically avoids "why" questions because the respondent can perceive "why"

Table 1

Informants' personal characteristics.

\begin{tabular}{|c|c|c|c|c|}
\hline Nickname & Age & Marital status & Occupation & Most important possessions/products \\
\hline Angela & 19 & Single & Student & Music CDs, mp3 player, contact lenses \\
\hline Lela & 21 & Single & Student & Music player, music CDs, laptop \\
\hline Mariah & 23 & Single & Student & Clothes, cross and chain, cosmetics \\
\hline Eva & 25 & Engaged & Secretary & Car, clothes, mobile phone, bibelot \\
\hline Victoria & 27 & Engaged & Architect assistant & Laptop, clothes, cosmetics, pet \\
\hline Elena & 28 & Engaged & Architect & Broach, laptop, clothes, tennis equip. \\
\hline Sofia & 29 & Married & Unemployed & Wed. ring, photos, organic products \\
\hline Melissa & 30 & Single & Pharmacist & Clothes, cosmetics, car, books \\
\hline Nancy & 31 & Single & Clerical & Car, mobile phone, clothes \\
\hline Fofika & 33 & Divorced & Mid-level manager & Car, laptop, house \\
\hline Mara & 34 & Married & Kindergarten teacher & Clothes, house, clothes, books, photos \\
\hline Nena & 36 & Single & Tour guide & Ring, heirloom jewelry, house, car \\
\hline Patca & 38 & Single & Pharmacist & Music CDs, paintings, books, clothes \\
\hline Irene & 40 & Married & Nurse & First car, teddy bears-souvenirs \\
\hline Julia & 43 & Married & White collar manager & Earrings, ring gift, organic products \\
\hline Zoi & 45 & Divorced & Piano teacher & Perfumes, cosmetics, car, piano, plants \\
\hline Maria & 46 & Married & Clerical & Necklace, house, perfume, clothes \\
\hline Popi & 47 & Married & Housewife & Broach, flat, medication, photos \\
\hline Mina & 48 & Married & Clerical & Furniture, cosmetics \\
\hline Sara & 49 & Married & Architect & Books, plants, house, clothes \\
\hline Alice & 50 & Married & Insurer & Baby clothes, souvenirs, flats, gifts \\
\hline Andy & 53 & Married & TV/radio producer & Piano, house \\
\hline Mary & 56 & Divorced & Tour guide & House, country house, cosmetics \\
\hline Nana & 57 & Separated & Housewife & Music CDs, clothes, bibelot, paintings \\
\hline Kara & 58 & Married & Housewife & Teddy bears, house, books, cosmetics \\
\hline Daphne & 60 & Separated & Teacher & Bible, laptop, houses, furniture, clothes \\
\hline Kate & 62 & Married & Retiree & Country house, tennis equip, cosmetics \\
\hline Lila & 63 & Married & Retiree & Clothes, furniture \\
\hline Joanna & 64 & Widow & Retired & Houses, lamp, furniture, books \\
\hline Rea & 65 & Single & Retired & Pet, flowers, gifts, perfume, mobile \\
\hline
\end{tabular}


questions as requests for rationalizations and for plausible explanations for his or her behavior and s/he may give defensive responses that do not focus on and therefore do not generate descriptions of the lived experience. The interviewer informed respondents that the study's purpose was to obtain insights into their experiences with their meaningful possessions and products; that the interview would be audio-taped; and she assured anonymity. The interviewer then asked respondents to describe their lives and their life-history focusing on major life experiences, core goals and decisions, and key life transition points (Tagg, 1985). To stimulate discussion about consumption the interviewer invited informants to "Tell the story" about their current and past meaningful possessions and products from acquisition onwards. The life-history technique (e.g. Denzin, 1978; Harrison, Veeck, \& Gentry, 2007) helped the informants unfold experiences and relationships over time. Even though longitudinal data would be useful as well, the life-story technique captured a sequence of respondents' experiences with important possessions/products. Analysis of the transcribed interviews using a phenomenologicalhermeneutical analysis (Thompson et al., 1990, 1989) entails a back and forth, part-to-whole interpretation mode in order to generate theory building around consumers' experiences with their selfrelevant possessions/products throughout the consumption cycle. This process continually challenges, modifies and revises the developing thematic structure. In order to relate to the respondents' reflections in a non-dogmatic fashion, the researchers employ no theories to impose meanings in the interpretation and primarily use an emic approach relying on participants' own terms/categories rather than those of the researchers. Then the researchers follow an etic interpretation linking the emic meanings to broader theoretical terms.

\section{Findings and discussion}

Findings suggest that the way consumers experience their valued possessions over time depends on the possession's meaning. That is, findings suggest a relationship between the meaning of the valued possession and the way the possession is experienced over time. According to the findings, three main trajectories (and variations on these combinations) track the evolving relationship of the self to the valued possession depending on the meaning of the possession. Sometimes the possession is appropriated to become part of the extended self over the course of time; at other times the possession is constantly part of the extended self from acquisition onwards; and at other times the possession can cease to be a part of the extended self and it is discarded. These trajectories depend on the reason the possession is valued, they often reflect life events and transitions in the consumer's life-story and do not necessarily reflect the object/ product use-life or object/product relevant factors such as functionality, technology, object's condition/appearance, or fashion. The following sections describe these three main trajectories in detail.

\subsection{Trajectory 1: possessions of rising value to the self; affiliation-related possessions}

Possessions in trajectory 1 are valued for representing, symbolizing and expressing affiliation and tend to have increasing importance to the self the longer they are possessed, reflecting the gradual building up and accretion of meanings to the possession. More specifically, over the course of time respondents value increasingly possessions associated with family members and loved ones such as jewelry and other gifts, furniture, souvenirs like old baby clothes, old toys, and other memorabilia that represent associations with important others and the preservation and maintenance of interpersonal and intergenerational ties. For example Alice ( 50 years old) says: "I now value and keep safely my children's old baby clothes and toys; old family photos; some handcrafts my mother had made as I love her and respect her a lot."
Not only do affiliation-linked objects gain in value the longer that they are possessed, but also over time respondents experience such possessions as irreplaceable; the participants resist replacing such possessions even with exact replicas, because they feel that the replica would not be able to sustain the same meaning as the original.

The increasing importance of the affiliation-related possession often reflects the building and strengthening of an interpersonal relationship with the passage of time (interpersonal ties grew in strength over time) and often results in the termination of the possession's usage. As the possession accumulates meaning, the possession is seen to be as of increasing importance and is therefore often stored for safekeeping in the longer run (due to fear of losing or damaging it), entering a curating period as the following quote illustrates: "I value a bracelet my partner gave me seven years ago; it was his first gift to me; once I almost lost it and I realized how sad I would be if I lost it, so I don't wear it anymore out of fear of losing it. It symbolizes our love" (Elena, aged 28).

Losing or damaging such possessions is often a concern of the respondents in the longer run, with the risk that loss or damage might connote disrespect for or lack of care towards the relationship and the person the possession is associated with. In some cases, affiliation related possessions are valued even though they are in a poor (functional or esthetic) condition and are therefore not used but stored safely as the following quote illustrates: "I love and value a broach my good friend and ex flat mate who I miss had given me...I don't want to lose this gift...sometimes I get stressed and I go and check whether it is in its position...I used to wear it a lot in the past but not anymore because it has faded ...it symbolizes my relationship with her" (Popi, aged 47).

Often the increasing importance of the possession reflects the increasingly nostalgic feelings about the loved person associated with the possession, especially if that person is absent (as Popi's story above) or has passed away as Mina's story (below) shows: "My mother in law gave us some classical furniture so we did not have to buy furniture in the beginning. We bought new, modern furniture that I prefer and we would give the old furniture back to her but she died so I kept the furniture and I love them now... I cannot give them away now...they remind me of her" (Mina, aged 48)

Mina's story is in line with Gentry, Kennedy, Paul, and Hill (1995) findings regarding the emotional attachment to possessions associated with a deceased loved one. Epp and Price (2008) suggest tracing the biography of an object and linking it to the personal biography in order to better understand symbolic consumption. Note that although Mina esthetically prefers modern furniture and although she bought her own furniture and her house is too small to appropriately accommodate so much furniture, Mina keeps and values the furniture of her mother-in-law who has now passed away. As Money (2007) suggests even esthetically displeasing objects can become strong markers of memory for consumers and be displayed prominently around the home. In some cases therefore, affiliation related possessions are valued increasingly over the course of time even though the possession is regarded as out of date or esthetically unpleasant or inappropriate for the respondent's life-stage. For example, over the course of time the teddy bear collection of Kara's children which they have had since they were young holds increasing emotional value for her, but because she feels teddy bears are inappropriate for her family's life-stage she uses these teddy bears strictly in private and hides them from the gaze of non-family members in order to avoid feelings of embarrassment. Over the course of time, Kara has developed a highly emotional, secretly held relationship with this teddy bear collection, a relationship considered risky if exposed to non-family members. She says, "It's childish but some old teddy bears of my kids become important to me and have names and roles inside our house... When we want to say something funny or sweet like I love you; we don't say it; they do. We hide them not to get embarrassed for having teddy bears besides our age" (Kara, aged 58). 
Overall, the increasing importance of an affiliation-related possession to the self reflects the gradual building up or accretion of meanings associated with the possession (rather like McCrcaken's (1988) patina). This finding is in line with Richins (1994a, 1994b) argument that the individual cultivates meanings through interactions with an object over time. For this reason, with the passage of time, affiliation related possessions are valued more even when they are no longer useful and are regarded as in a poor (functional or esthetic) condition, esthetically displeasing, out of date or inappropriate for the respondent's life-stage. In addition, this study's findings contradict to a certain extent previous research findings according to which people in later stages of the life cycle emphasize the interpersonal aspects of their possessions (Kamptner, 1991; Wallendorf \& Arnould, 1988) and value memorabilia cues (i.e., sentimental objects used privately) (Csiicszentmihalyi \& Rochberg-Halton, 1981).

Respondents both in earlier and in later stages of the life cycle value possessions for their interpersonal aspects (e.g. both younger and older respondents value souvenirs for associating these items with their loved-ones), aligning with Kleine, Kleine, and Allen (1995) argument that attachment is not predicted by possession type, or person type; but rather a specific person-object pairing is idiosyncratic to the specific life story episode it narrates. Finally, the findings demonstrate that objects are irreplaceable to the extent that they retain indexical or iconic associations (Belk, 1988; Curasi et al., 2004; Kopytoff, 1986; McCracken 1988; Miller, 1987).

\subsection{Trajectory 2: possessions of declining value to the self; differentiation-linked possessions}

Possessions valued for differentiating the self from others, are often intensely identified with the self as parts of the consumer's extended self the closer in time that the possession is to its point of acquisition. These possessions are valued for symbolizing and for transforming the self into a distinctive and/or autonomous desired form and tend to be valued for a shorter period of time. These possessions that give respondents the sense of distinction/standing out and/ or autonomy/control, tend to be of declining importance to the self and to be disposed of willingly (and often replaced) in the longer run. More specifically:

\subsubsection{Possessions associated with standing out/positive distinction}

Respondents value personal appearance goods acquired recently for representing or enabling positive distinction such as looking youthful, feminine and modern and for preventing negative standing out such as having an old-fashioned and conservative appearance. For example, Angela values her first and recently acquired contact lenses feeling they enable her to look beautiful. She says, "Lately, I started wearing contact lenses; they are important to me. I was not feeling beautiful with my glasses but my parents would not let me wear contact lenses as a child in order to avoid infections. In the future, I may have an operation to stop wearing lenses" (Angela aged 19).

Angela's relationship with her contact lenses is an avoidancedriven relationship (Fournier, 1998) that is a union precipitated by the desire to move away from a prior partner (eyeglasses), as opposed to attraction to a chosen partner per se (contact lenses). In general, such goods valued for representing and enabling the self to stand out positively, have declining importance for the respondents. Such goods are valued the most the closer they were to their acquisition point but (although they were functional, in good condition and/or up to date) they start losing their power to provide satisfaction over time (in the longer run), as the following quotes illustrate:

"I want to look classy so when clothes or cosmetics are new, they are important to me for a little while; I feel them mine more. We exchange clothes with my sister but when we buy new ones we don't want to share them in the beginning" (Melissa, aged 30).
"Clothes are special to me in the beginning when I buy them. After a while they don't make any particular impression on me. I like to wear fashionable, not conservative clothes. I want to wear clothes that fit me, clothes I look nice and beautiful in" (Mariah, 23 years old).

"I always want to buy new clothes; clothes are important to me especially when they are new; I like the jeans and t-shirts I bought recently as they are youthful and feminine" (Mara, 34 years old).

The above quotes refer to relationships with possessions and products that could be characterized as 'flings' (Fournier, 1998) as they are short-term, time-bounded relationships of high emotional reward, but devoid of commitment. Respondents are often only briefly satisfied by such possessions associated with distinction reflecting the notion of an empty self (Baudrillard, 1988; Cushman, 1990; Gergen, 1991; Jameson, 1990) that seeks the experience of being continually filled up by consuming goods.

\subsubsection{Possessions associated with autonomy/control}

Several respondents value their cars for satisfying autonomy and control needs and say that their cars had high importance to them around the time of acquisition as the following quote indicates, "My car is important to me [...] in the beginning when I first bought it, it made more impression on me; I would feel its newness; and it was giving me more the intense sense of freedom, independence and energy" (Eva, 25 years old).

Respondents value first and recently acquired cars the most as important and meaningful possessions that provide autonomy and control. For example, Nancy (31 years old) and Fofika (33 years old) say about their first and recently acquired car: "I adore my car...it enables me to go anywhere I want. I don't want to depend on others for transportation. I can choose time of departure and place to go to. It gives me independence..." (Nancy 31 years old). "I am happy for getting the car few months ago. I liked it immediately. It is a terrific medium of escape. I go through tough phases but I escape with car rides and I calm down" (Fofika 33 years old).

The intensity of positive feelings towards such autonomy related possessions is directly related to how recently the women acquired the possessions and often such possessions are of declining importance to the respondents well before the introduction of new, replacement models. Several respondents shared that they valued more and took better care of their current cars when the latter were recently acquired. Furthermore, several respondents said that they valued and took care of their current cars because the vehicles gave them a sense of autonomy but not to the same extent as they had valued and cared for their very first cars. For example, Irene ( 40 years old) says, "I loved my first car. In the beginning I was using cover sheets on the seats and I used to wash and clean it very often. I never did such things for a car again; I really wanted it; it was symbolizing my freedom; I could go everywhere I wanted anytime. I replaced it later as it was old."

Note that such possessions valued for providing a sense of autonomy (and control) have declining importance for the respondents, reflecting respondents' declining need for autonomy, when autonomy needs have been satisfied. As a respondent says "when you have autonomy, you take it for granted and you don't appreciate it" (Mary 56 years old). As Shimp and Madden (1988) suggest the level of yearning for an object can co-vary with experience. Consumers can experience great passion (yearning) for an object upon initial experience with it but this yearning should subside over time as the consumer acquires more experience with the object (Richins \& Block, 1986).

In addition, several respondents valued their laptops for facilitating their good academic or professional standing, giving the respondents a sense of control (and sometimes positive distinction). The intensity 
of feelings was directly related to how recently the laptops have been acquired and sometimes these are the first laptops owned by the respondents. Furthermore, note that often such possessions associated with autonomy and distinction are of declining importance to the self even while object relevant factors (e.g. functionality, technology, object condition/appearance, fashion) are still stable. This finding is the opposite case from the previously discussed possessions associated with affiliation (trajectory 1) that are of increasing importance to the self even when object relevant factors have changed (loss in functionality, object's poor condition, changes to the morphological characteristics of the object, change in object's appearance, obsolescence, technological improvements, fashion changes and introduction of replacement models).

3.3. Trajectory 3: possessions of steady value to the self; associated with recreation, security, nurturance and transitions related to loved ones

Respondents value possessions associated with recreation (often books and music CDs), security (e.g. medication), nurturance (e.g. houses) and transitions related to loved ones (e.g. wedding ring). These possessions tended to have steady importance to the self, are intensely identified with the self, and used often extensively, from acquisition onwards:

\subsubsection{Possessions associated with recreation}

The respondents often value possessions for recreational reasons (often music CDs, music players, pianos, books, movies, country houses and equipment related to hobbies such as riding, tennis, painting, gardening or pottery). These possessions are intensely and constantly valued from acquisition onwards and are used frequently during leisure time for providing enjoyment/pleasure and/or preventing or offering relief from pressure and tiredness as the following quotes illustrate: "Our country house is an outlet; it relaxes us; takes away pressure" (Kate aged 62). "My music CDs and mp3 player are always important to me...Music accompanies me in my best and worst moments; I enjoy and relax with music" (Angela, aged 19). "My piano is and always was important to me. I adore music; I cannot live without music. Music and the piano relax me and calm me down, I become happy with music" (Andy aged 53).

Respondents tended to experience such possessions as valuable but replaceable, as they would be willing to substitute them when object relevant factors change (e.g. functionality loss, obsolescence).

\subsubsection{Possessions associated with security}

Possessions and products associated with physical and financial security are also valued constantly and used extensively from acquisition onwards provided that object relevant factors (e.g. functionality, technology) remain stable. More specifically, the respondents value organic healthy products, exercise-related items, medication, religiously-linked possessions such as crosses and chains and the Bible, items used for educational or professional reasons such as books and PCs, houses and mobile phones for the sense of security they feel they acquire from such items. For example, a respondent values the Bible as her most important possession; she feels the Bible enables her desired self "secure, feeling certainty". She says: "I first read the Bible in prison during dictatorship; I had taken action against the dictatorial regime. I was in danger; nobody could help me. I found support in the Bible; it changed me. I understood that God loves me; since then I follow His advice as it is the best for me. Before that I used to pursue my wants even without being safe. Now, I set His opinions as my 'musts'. In this way I obtain the certainty that I walk in the right route" (Daphne, 60 years old).

Another respondent constantly values her cross and chain, feeling it enables her desired "protected" self. "A platinum cross and chain is important to me. Usually I have this cross with me at important moments, when I am stressed; for example I had it with me in all my exams; the exams to enter the university, the undergraduate and postgraduate exams [...] When I get stressed and I get stressed very easily I feel better by having the cross necklace with me; I feel I will be and do better by wearing it, I feel protection...I don't feel insecure. The cross necklace is important to me for the sense of connection with God it gives me" (Mariah, 23 years old).

Another example is Rea who values her mobile phone for the security she feels it provides: "My mobile phone is necessary to me; I get lost without it; I wonder how we used to live without mobile phones before; you feel safe as you can communicate with people immediately and get help anytime" (Rea, 65 years old).

Often these security linked possessions are experienced as replaceable; respondents would be willing to substitute them if object relevant factors change (e.g. loss in functionality, technological improvements and introductions of new objects, changes in object's condition).

\subsubsection{Possessions associated with nurturance}

Respondents often value possessions for enabling them to offer care to loved ones. These possessions are associated with care giving (e.g. houses, presents to their loved ones, pets) and are always important to the respondents, often reflecting an already significant relationship with an important other. These possessions are used, shared with or offered to loved ones. For example, several respondents value their flats and houses as with these possessions they could provide for their (adult) children for example with shelter and/or financial aid. The following quotes illustrate these findings: "Lately, I bought from my brother the apartment I got raised in... It's an emotionally important purchase as my parents would be sad if the flat with all the memories would pass to foreigners... I'll give the house to my child to live on her own. I have to take care and protect my daughter and my parents" (Popi, aged 47). "I want my sons to have a decent life with less anxiety for the next day. I'm satisfied I bought a house to allocate my belongings to my sons later on fairly and in a way that gives them security in life" (Joanna aged 64).

Another example is Rea (65 years old) who expresses her constant loving feelings for her plants, dog and items she offers to her loved ones, for enabling and representing nurturance, revealing a desired "mothering" identity. She says: "My plants are important to me; I take care of them; they are living creatures; they understand I love and care about them [...]I also take care of my sweet child; that is my dog $[\ldots]$ also the things I buy for my spiritual son are important to me. I love him and care about him. I always find something nice for him in my trips."

\subsubsection{Possessions associated with transitions related to loved ones}

The participants often value possessions for symbolizing positive transitions associated with important others and interpersonal ties (e.g. marriage, motherhood, engagement to be married). More specifically, respondents value possessions that symbolize transitions in regard to their loved-ones such as engagement and wedding rings, jewelry gifts or self-gifts to celebrate the birth of a son or daughter. These possessions representing positive transitions related to loved ones are consistently important for the respondents and this fact is reflected in respondents' preoccupation with wearing the possession associated with positive affiliation-related transitions (i.e. marriage, engagement, motherhood) at all times. Possessions that express positive transitions are valued intensively from acquisition onwards reflecting and standing for a significant relationship with an important other formed at/around acquisition as the following quotes from respondents' stories indicate: "My wedding ring symbolizes our marriage, our life vows, our love" (Sofia, aged 29). "If I lost this necklace I would die from a broken heart ...I bought it when I gave birth to my daughter. I promised always to wear it. I've never removed it for 18 years now...not even on the beach, in the shower or when I sleep. I always wear it. I've associated it with my daughter's 
birth; the happiest moment in my life. Although I hadn't realized what it means to be a parent...I feel my daughter is like this necklace; she is part of me...it is this connection" (Maria, aged 46).

Respondents are often attached to such possessions that reflect role (e.g. mother, wife) identities (Solomon \& Buchanan, 1991). Such possessions that are valued steadily for representing transitions in regard to loved ones, tend to be experienced as irreplaceable; respondents feel that even a physically identical material object would not be able to sustain the same meaning as their own possession. For example, Julia always values as irreplaceable a gold solitaire ring that was a gift from her husband when she gave birth to their son. This one stone ring symbolizes family binding/connection due to the birth of her son and is always highly important for Julia as she associates it with her desired self "belonging". She says: "We are all the three together in this ring... it is the binding with my husband due to my son."

\section{Variations}

Variations on these trajectories have also been identified (transitions from one trajectory to another). In some cases, the meaning a respondent assigns to her possession changes over time and this change is reflected in the possession-self relationship trajectory. For example, the self-possession relationship follows a steadydeclining-steady trajectory when possessions become associated with negative transitions. For instance, the termination of her engagement influenced a respondent's relationship with her engagement ring. Although she highly valued her ring at the beginning, later on she valued it but less as it started evoking for her both positive and negative memories and bitter-sweet feelings, reflecting a past but not currently existing significant relationship with an important other. For that reason she keeps it safely but she does not wear it. Reflecting consumer ambivalent feelings (Nelson \& Otnes, 2005), she says: "My broken engagement ring is important to me... I keep it but I don't wear it ... at the end the relationship became unfair for me. I was only giving. He didn't want to give back" (Nena, aged 36). As the example demonstrates symbolic objects can be imbued with meaning that shifts over time (Belk \& Costa, 1998; Epp \& Price, 2008, 2010; Miller, 1987).

\section{Alternative consumer-possession relationship development trajectories}

Based on these informants' retrospective histories of their material objects and following Fournier's (1998) informants' own visual depictions of the developmental courses of their primary brand relationships, Fig. 1 provides alternative consumer-possession relationship development trajectories.

\section{Conclusion}

This study highlights how the self relates to possessions throughout the consumption cycle and provides a framework for better understanding the dynamic relationships consumers form with their possessions. In line with the discovery-oriented project goals, the authors offer these interpretations as plausible and supported by the transcriptions, but the authors do not claim to have developed an exhaustive account. The present interpretation focuses on the women's experiences in a particular socio-historical context. Different insights could emerge across different settings. Further insights into the person-object relationship over time and how it is influenced by shifts of identities, context and product factors could be gained from a longitudinal study. In addition, possession-self relationships throughout the consumption cycle for male consumers are another issue future research can explore.

This study's findings are in line with work from consumer researchers who focus on consumers' possessions and acknowledge that relationships with possessions involve the provision of meanings to the consumer; meanings used for self-definition (Belk, 1988; Kleine et al., 1995; McCrcaken, 1988; Richins, 1994b; Wallendorf \& Arnould, 1988). This study extends theory on symbolic consumption by examining consumers' experiences with their meaningful possessions/products throughout the consumption cycle; and proposing three main trajectories that map the relationship of the self to the valued possession depending on the meaning/reason for valuing the possession. The present study's findings therefore contradict to a certain extent Epp and Price's (2010) argument that in contemporary consumer culture, uncertain trajectories are depicted by object biographies (Hurdley, 2006; Kopytoff, 1986), as well as by personal biographies, as evidenced in diverse identity practices (Ahuvia, 2005; Reed \& Bolton, 2005; Warde, 2005). And by examining an object's trajectory from the perspective of the consumer this study adds to Kopytoff's study that only focuses on the object per se and to the understanding of how the object-consumer relationship evolves.

Finally, marketing managers/strategists need to understand consumers' evolving relationships and experiences with and behaviors towards their meaningful possessions/products throughout the consumption cycle. Products become part of consumers' extended selves either before acquisition or afterwards. Mittal (2006) suggests that products need identity-engaging communications and 'involving' acquisition settings in order to become part of consumers' extended selves before acquisition, while connection-building product use
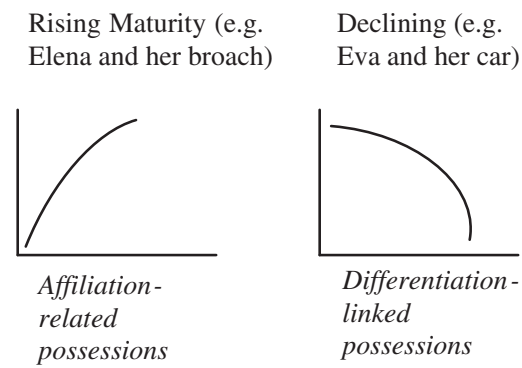

Plateau (e.g. Andy and her piano)

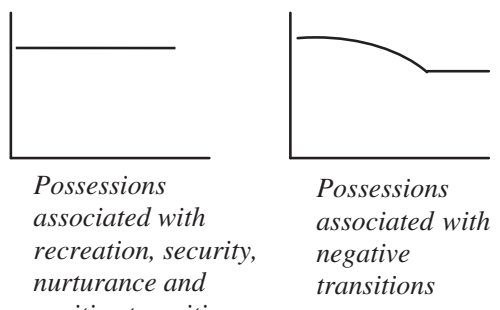

positive transitions

regarding loved-ones
Plateau-declining-plateau

(e.g. Nena and her ring)

NOTE: Time on X-axis; closeness on Y-axis.

Fig. 1. Alternative consumer-possession relationship development trajectories. 
experiences would need to be simulated in post-acquisition, usageoriented marketing events, for products to become part of consumers' extended selves after acquisition. The present study's findings suggest that the meaning associated with a product plays an important role in whether or not the product becomes part of the consumer's extended self before or after acquisition. Marketing managers/strategists could use this understanding in the development of communication and channel strategies for the positioning and branding of goods.

\section{References}

Ahuvia AC. Beyond the extended self: loved objects and consumers' identity narratives. Journal of Consumer Research 2005;32:171-84.

Applbaum K, Jordt I. Notes toward an application of McCracken's "cultural categories" for cross-cultural consumer research. Journal of Consumer Research 1996;23: 204-18.

Baudrillard J. Consumer society. In: Poster Mark, editor. Baudrillard: selected writings. Stanford: Stanford University Press; 1988. p. 32-60.

Belk RW. Possessions \& the extended self. Journal of Consumer Research 1988;15(2): 139-68.

Belk RW. Moving possessions - an analysis based on personal documents from the 1847-1869 Mormon migration. Journal of Consumer Research 1992;19(3): 339-61.

Belk RW, Costa JA. The mountain man myth: a contemporary consuming fantasy Journal of Consumer Research 1998;25(3):218-40.

Belk RW, Wallendorf M. Of mice and men: gender identity in collecting. In: Martinez Katharine, Ames Kenneth L, editors. The material culture of gender, the gender of material culture. Hanover and London: University Press of New England; 1997.

Belk RW, Wallendorf M, Sherry J. The sacred and the profane in consumer behaviour: theodicy on the odyssey. Journal of Consumer Research 1989;16(1):1-38.

Belk RW, Ger G, Askegaard S. The fire of desire: a multisited inquiry into consumer passion. Journal of Consumer Research 2003;30(3):326-51.

Bell SS, Holbrook MB, Solomon MR. Combining esthetic \& social value to explain preferences for product styles with incorporation of personality \& ensemble effects. Journal of Social Behaviour \& Personality 1991;6(6):243-74.

Colaizzi PF. Psychological research as the phenomenologist views it. In: Valle, King, editors. Existential phenomenology, alternatives for psychology. NY: Oxford University Press; 1978.

Csiicszentmihalyi M, Rochberg-Halton E. The meaning of things: domestic symbols and the self. New York: Cambridge University Press; 1981.

Curasi CF, Price LL, Arnould EJ. How individuals' cherished possessions become families' inalienable wealth. Journal of Consumer Research 2004;31(3):609-22.

Cushman P. Why the self is empty: toward a historically situated psychology. American Psychologist 1990;45(5):599-611.

Denzin NA. The comparative life history method. The Research Act: a theoretical introduction to sociological research methods. NY: McGraw-Hill; 1978. p. 214-55.

Dittmar H. Meanings of material possessions as reflections of identity: gender \& social material position in society. Journal of Social Behaviour \& Personality 1991;6(6): $165-86$.

Dittmar H. The social psychology of material possessions: to have is to be. PrenticeHall; 1992.

Elliot R, Wattanasuwan K. Consumption and the symbolic project of the self. European Advances in Consumer Research 1998;3:17-20.

Epp AM, Price LL. Family identity: a framework of identity interplay in consumption practices. Journal of Consumer Research 2008;35:50-70.

Epp AM, Price LL. The storied life of singularized objects: forces of agency and network transformation. Journal of Consumer Research 2010;36:820-37.

Fournier S. Consumers and their brands: developing relationship theory in consumer research. Journal of Consumer Research 1998;24(4):343-53.

Gentry JW, Kennedy PF, Paul C, Hill RP. Family transitions during grief: discontinuities in household consumption patterns. Journal of Business Research 1995;34(1): 67-79.

Gergen K. Saturated self: dilemmas of identity in contemporary life. NY: basic books; 1991.

Grayson K, Shulman D. Indexicality and the verihcation function of irreplaceable possessions: a semiotic analysis. Journal of Consumer Research 2000;27:17-30.

Harrison RL, Veeck A, Gentry JW. A life course perspective of family meals via the life grid method. Advances in Consumer Research 2007;35:758.

Hogg MK, Michell PCN. Identity, self and consumption: a conceptual framework. Journal of Marketing Management 1996;12(7):629-44.

Holt BD. Why do brands cause trouble? A dialectical theory of consumer culture \& branding. Journal of Consumer Research 2002;29(1):70-90.

Hurdley R. Dismantling mantelpieces: narrating identities and materializing culture in the home. Sociology 2006;40(4):717-33.
Jameson F. Post modernism \& consumer society. In: Foster Hal, editor. Postmodern culture. London: Pluto; 1990. p. 111-26.

Kamptner NL. Personal possessions and their meanings in old age. In: Spacapan Shirlynn, Oskamp Stuart, editors. The social psychology of aging. Newbury Park, CA: Sage; 1989. p. 165-96.

Kamptner NL. Personal possessions \& their meanings: a life span perspective. Journal of Social Behavior \& Personality 1991;6(6):209-28.

Kleine S, Baker S. An integrative review of material possession attachment. Academy of Marketing Science Review 2004;2004(1):1-35

Kleine S, Kleine R, Allen C. How is a possession 'me' or 'not me'? Characterizing types of an antecedent of material possession attachment. Journal of Consumer Research 1995;22(3):327-43.

Kopytoff I. The cultural biography of things: commoditization as process. In: Appadurai Arjun, editor. The social life of things: commodities in cultural perspective. Cambridge University Press; 1986. p. 64-95.

Kvale S. The qualitative research interview: a phenomenological \& a hermeneutical mode of understanding. Phenomenological Psychology 1983;14(2):171-96.

Lastovicka JL, Fernandez KV. Three paths to disposition: the movement of meaningful possessions to strangers. Journal of Consumer Research 2005;31(4):813-23.

McCracken GD. Culture and consumption: new approaches to the symbolic character of consumer goods and activities. Indiana University Press; 1988 (chapter 2).

Miller D. Material culture and mass consumption. Oxford: Blackwell; 1987.

Mittal B. I, me, and mine - how products become consumers' extended selves. Journal of Consumer Behaviour 2006;5(6):550-62.

Money A. Material culture and the living room: the appropriation and use of goods in everyday life. Journal of Consumer Culture 2007;7(3):355-77.

Myers E. Phenomenological analysis of the importance of special possessions. Advance in Consumer Research 1985;12:560-5.

Nelson MR, Otnes CC. Exploring cross-cultural ambivalence: a netnography of intercultural wedding message boards. Journal of Business Research 2005;58(1):89-95.

Olmsted AD. Collecting: leisure, investment or obsession? Journal of Social Behavior and Personality 1991;6(6):287-306.

Price L, Arnould E, Curasi C. Older consumers' disposition of valued possessions. Journal of Consumer Research 2000;27:179-201. (Sept.).

Reed II A, Bolton LE. The complexity of identity. MIT Sloan management review 2005: 18-22. (Spring).

Richins ML. Special possessions and the expression of material values. Journal of Consumer Research 1994a;21:522-33.

Richins ML. Valuing things: the public \& private meanings of possessions. (Dec) Journal of Consumer Research 1994b;21:504-21.

Richins ML, Block P. After the new wears off: the temporal context of product involvement. Journal of Consumer Research 1986;13:280-5. (Sept.).

Roster CA. Letting go: the process and meaning of dispossession in the lives of consumers. Advances in Consumer Research 2001;29:425-30.

Sherman E, Newman ES (1977-1978). The Meaning of Cherished Personal Possessions for the Elderly, Journal of Aging \& Human Development, 8, 181-192.

Shimp T, Madden T. Consumer-object relations: a conceptual framework based analogously on Stemnberg's triangular theory of love. Advances in Consumer Research 1988; $15: 163-8$.

Solomon MR, Buchanan B. A role-theoretic approach to product symbolism: mapping a consumption constellation. Journal of Business Research 1991;22:96-109.

Tagg SK. Life story interviews and their interpretation. In: Brenner Michael, Brown Jennifer, Canter David, editors. The research interview, uses and approaches. London: Academic Press: 1985. p. 163-99.

Thompson CJ. Caring consumers: gendered consumption meanings and the juggling lifestyle. Journal of Consumer Research 1996;22(4):388-407.

Thompson CJ, Pollio HR, Locander WB. Putting consumer experience back into consumer research: the philosophy and method of existential-phenomenology. Journal of Consumer Research 1989;16:133-46.

Thompson CJ, Locander WB, Pollio HR. The lived meaning of free choice: an existentialphenomenological description of everyday consumer experiences of contemporary married women. Journal of Consumer Research 1990;17:346-61.

Wallendorf M, Arnould E. My favorite things: a cross-cultural inquiry into object attachment, possessiveness \& social linkage. Journal of Consumer Research 1988;14(4):531-47.

Wapner S, Demick J, Redondo JP. Cherished possessions \& adaptation of older people to nursing homes. International Journal of Aging \& Human Development 1990;31(3): 219-35.

Warde A. Consumption \& theories of practice. Journal of Consumer Culture 2005;5(2): 131-53.

Wells W. Discovery-oriented consumer research. Journal of Consumer Research 1993:19:489-504.

Wicklund \& Goliwitzer. Symbolic self completion. Hilisdale, NJ: Lawrence Erlbaum; 1982.

Young MM, Wallendorf M. Ashes to ashes, dust to dust: conceptualizing consumer disposition of possessions. In: Childers, et al., editor. American Marketing Association Proceedings of the AMA Winter Educators Conference, Chicago; 1989. p. 33. 